\section{Pulmonary hypertension after lung irradiation in infancy}

Irradiation of the lung may lead to several complications including pneumonitis, pulmonary fibrosis, pleural effusion, and pneumothorax. The development of pulmonary hypertension is less well known and was not recorded in either of two recent reviews of the complications of radiotherapy. ${ }^{2}$ We report a case here.

\section{Case report}

A 14-year-old girl presented with an 18-month history of syncope and mild dyspnoea on effort. At the age of 7 months a neuroblastoma arising from the left of the thoracic spine had been resected. Histology had shown severe cystic degeneration of the tumour. Postoperatively, irradiation had been given by linear accelerator in 55 exposures over eight weeks (tumour dose 3500 rads, given dose 2041 rads to the posterior mediastinum; given dose 2372 rads to the anterior mediastinum). A further 200 rads had been given to the left lower chest for a presumed metastasis arising in the scar area. She had remained well until the onset of syncope at the age of 12 years.

On examination she was small (height $153 \mathrm{~cm}$, weight $40 \mathrm{~kg}$ ) with underdevelopment of the left side of the chest and the left breast. There was no cyanosis or finger clubbing. Blood pressure was $120 / 70 \mathrm{~mm} \mathrm{Hg}$. Jugular venous pressure was raised to the angle of the jaw. There was a left parasternal heave of right ventricular hypertrophy. The pulmonary second sound

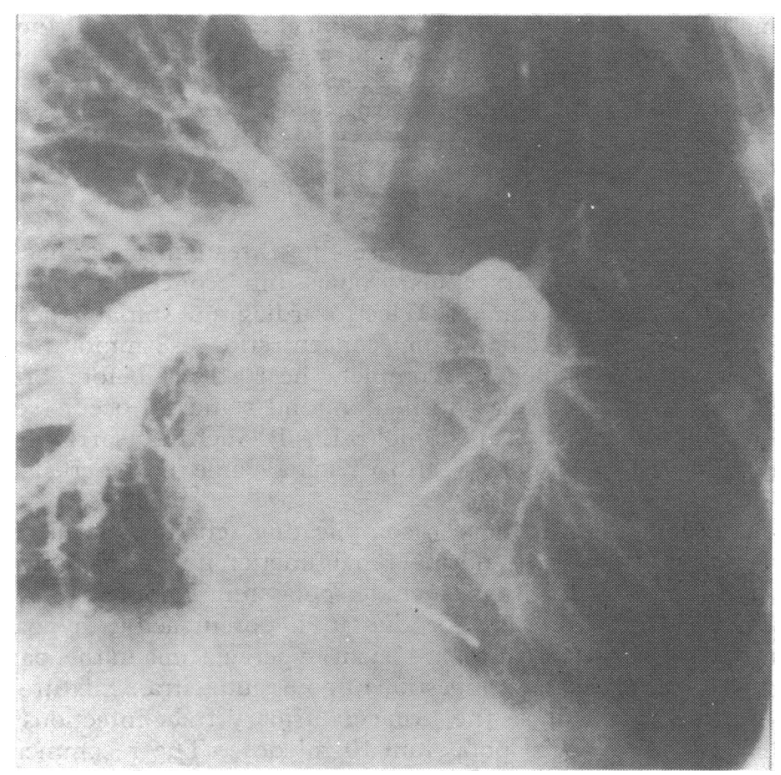

Pulmonary arteriogram: right pulmonary artery and branches are normal; left pulmonary artery is small, with severe reduction in number and size of its branches.

was accentuated. There were signs of functional tricuspid regurgitation, with a soft pansystolic murmur at the left sternal edge increasing on inspiration together with a third heart sound. The liver was enlarged $3 \mathrm{~cm}$ below the subcostal margin and was slightly pulsatile. There was no peripheral oedema. Breath sounds were normal.

An electrocardiogram showed sinus rhythm, an axis of $+150^{\prime \prime}$, right atrial enlargement, and right ventricular hypertrophy with a tall $R$ wave in V1 of $20 \mathrm{~mm}$, and the amplitude of the $S$ wave equal to that of the $R$ wave in V6 $(9 \mathrm{~mm})$. Chest $x$-ray examination showed underdevelopment of the left side of the chest with mild crowding of the ribs and slight kyphoscoliosis convex to the left. The cardiothoracic ratio was $48 \%$. The lung fields on each side seemed normal and there was no fibrosis. An echocardiogram showed an enlarged right ventricle of $3 \mathrm{~cm}$ diameter but was otherwise normal.

Lung function tests showed a restrictive pattern with a diminished transfer factor of 10.1 (predicted 22.0 ) $\mathrm{ml} / \mathrm{min} / \mathrm{mm} \mathrm{Hg}$. At cardiac catheterisation the pressures were $(\mathrm{mm} \mathrm{Hg})$ : right atrium $\mathrm{a}=15, \mathrm{x}=10, \mathrm{v}=15, \mathrm{y}=7$, mean $=12$; right ventricle $70 / 16$; and pulmonary artery $70 / 30$. Systemic arterial pressure was $95 / 70 \mathrm{~mm} \mathrm{Hg}$. A satisfactory wedge pressure was not obtainable. There was no intracradic shunt on oximetry. Systemic saturation was $100 \%$. Blood gas tensions were normal. Haemoglobin concentration was $15.4 \mathrm{~g} / \mathrm{dl}$. A pulmonary arteriogram (figure) showed a normal right pulmonary artery but the branches to the left were small, spidery, and hypoplastic. The pulmonary veins from the left lung were underdeveloped. Follow-through to the left side of the heart and aorta was normal, and there was no evidence of a ventricular septal defect.

\section{Comment}

The pulmonary vasculature is sensitive to irradiation and, if the dose is sufficient, reduced perfusion on lung scans, pneumonitis, and late pulmonary fibrosis seen on chest $x$-ray films may develop. ${ }^{3}$ Irradiation in infancy also inhibits the proliferation of alveoli and pulmonary vasculature and considerably reduces the subsequent size of the lung and chest wall. ${ }^{4}$ Both these mechanisms were probably acting to produce the late development of pulmonary hypertension in this patient.

Information on the $x$-ray fields used in this case was not available, but the dose of irradiation was high and protracted over an unusually long period. The outcome emphasises that every attempt should be made, especially in children, to keep the dose and field of therapeutic irradiation to a minimum.

We thank Dr L Arthur, consultant paediatrician, Derby Children's Hospital, who referred this patient, and $\mathrm{Dr} \mathrm{N}$ Nicol, consultant radiotherapist, Leicester Royal Infirmary, for advice on the radiotherapy aspects of the case.

Requests for reprints should be sent to Dr P J B Hubner.

1 Gross NJ. Pulmonary effects of radiation therapy. Ann Intern Med 1977; $86: 81-92$.

2 Strickland P. Complications of radiotherapy. Br F Hosp Med 1980;23: 552-61.

${ }^{3}$ Goldman SM, Freeman LM, Ghossein NA, Sanfilippo LJ. Effects of thoracic irradiation on pulmonary arterial perfusion in man. Radiology $1969 ; 93: 289-96$.

'Wohl MEB, Griscom NT, Traggis DG, Jaffe N. Effects of therapeutic irradiation delivered in early childhood upon subsequent lung function. Pediatrics 1975;55:507-16.

(Accepted 18 August 1981)

Department of Cardiology, Groby Road Hospital, Leicester LE3 9QE

$P$ BUTLER, MB, MRCP, senior house officer (present appointment: registrar in diagnostic radiology, Manchester AHA(T))

$P$ CHAHAL, MB, MRCP, senior house officer (present appointment : registrar Department of medicine, Hammersmith Hospital, London $\mathbf{W} 12 \mathrm{OHS}$ )

N M HUDSON, MB, FRCR, consultant radiologist

P J B HUBNER, MB, MRCP, consultant cardiologist

\section{Peripheral oedema in patients treated with isosorbide dinitrate}

Isosorbide dinitrate is widely used to treat angina and increasingly to manage congestive cardiac failure. ${ }^{1}$ Reported side effects are headache, flushing, and postural hypotension. ${ }^{2}$ I report three cases which suggest that it may also cause peripheral oedema.

\section{Case reports}

Case 1-A 74-year-old man with a history of myocardial infarction was admitted with central chest pain. There was clinical and radiographic evidence of left heart failure but his jugular venous pressure was normal and there was no peripheral oedema. Electrocardiograms showed sinus rhythm and acute ischaemia. Cardiac enzyme activities and tests of renal and hepatic function were normal. He was treated with bumetanide $1 \mathrm{mg}$ daily and isosorbide dinitrate $10 \mathrm{mg}$ three times daily. Chest pain did not recur. Signs of left heart failure resolved in 24 hours and a chest $x$-ray film three days later was normal. Six days after admission bilateral pitting ankle oedema was noted; jugular venous pressure was normal and there was no clinical evidence of left heart failure. Echocardiography showed normal right and left ventricular dimensions. The electrocardiogram was unchanged. Bumetanide $1 \mathrm{mg}$ daily was continued and isosorbide withdrawn; the ankle oedema resolved within 36 hours. Isosorbide was reintroduced when he was fully ambulant; the oedema did not recur.

Case 2-A 69-year-old man was admitted with central chest pain. There was clinical and radiographic evidence of left heart failure but the jugular venous pressure was normal and he had no peripheral oedema. Electrocardiograms showed sinus rhythm and anterior subendocardial infarction. Cardiac enzyme activities were raised and renal and hepatic function normal. He 